\title{
STRESS-STRAIN MODEL FOR PRESTRESSING STEEL WITH CYCLIC LOADING
}

\author{
K. J. Thompson* and R. Park**
}

\begin{abstract}
SUMMARY
Experimental stress-strain curves for repeated tensile loading of 0.276 in $(7 \mathrm{~mm})$ diameter prestressing steel wire in the inelastic range are presented. A mathematical model employing a modified form of the Ramberg-Osgood function is proposed to describe the cyclic stress-strain behaviour of the prestressing steel. The experimental stress-strain results are subjected to regression analysis in order to obtain empirical expressions for the constants in the Ramberg-Osgood function. The constants are found to depend on the strain imposed in the previous loading run and the characteristics of the monotonic stress-strain curve. The stressstrain curve for monotonic loading, with suitably adjusted origin of coordinates in the case of significant reversed loads, is used to describe the envelope curve which the steel stresses cannot exceed. The proposed cyclic stress-strain model predicted the experimental curves with good accuracy.
\end{abstract}

\section{INTRODUCTION}

Structural elements may be subjected to cyclic (reversed) loading well into the inelastic range during severe earthquakes. In order to predict the response of a prestressed concrete structure to severe earthquakes, accurate stress-strain information is required for the behaviour of prestressing steel under cyclic loading in the inelastic range. Such stress-strain curves can be used to determine theoretical moment-curvature relationships for prestressed concrete members subjected to cyclic loading $(1,2,3)$, from which the nonlinear dynamic responses of prestressed concrete structures may be predicted.

It has been assumed by some investigators, for example Paranagama and Edwards' $(4)$, that the unloading path and the initial part of the reloading path of the stress-strain curve for prestressing steel under repeated loading are coincident. However, as has been shown by Blakeley and Park $(1,2)$, a considerable amount of hysteris can in fact exist in such unloading-reloading stress-strain cycles, particularly at high strains. Also, there is a reduction in the slope of the linear portion of the unloading curve with increasing maximum strain. A stress-strain model describing this behaviour of prestressing steel has been presented by Blakeley and Park $(1,2)$. Their model idealised the stress-strain hysteresis loops as a series of straight lines, and the width of the hysteresis loop and the slope of the unloading curve was taken as a function of the modulus of elasticity and the maximum steel strain sustained.

Although this model is reasonably accurate, it is evident that it could be improved by the use of curved loops rather than loops constructed from series of straight lines.

* Senior Engineer, Ministry of Works and Development, Invercargill.

* * Professor of Civil Engineering, University of Canterbury, Christchurch.
The paper presents further stress-strain test results for high tensile steel specimens under repeated loading and presents empirical equations which model the curved stress-strain loops. A more detailed account of this work may be seen elsewhere (3) ENVELOPE STRESS-STRAIN CURVES

Envelope for Repeated Loading of Same Sign

It is assumed that the stress-strain curve for monotonic loading forms an envelope stress-strain curve for repeated loading of the same sign. The origin of the envelope curve is taken as $(0,0)$ on the stress-strain axes. This assumption is the same as that adopted by Blakeley and Park $(1,2)$ and was justified by observation of their test results. The monotonic stressstrain curve assumed in this study $(1,2)$ is illustrated in Fig. 1. The curve comprises three regions, consisting of two straight lines connected by a hyperbolic curve, which may be represented by the following equations using the notation of Fig. 1 :

Region IA:

$\varepsilon_{p} \leqslant \varepsilon_{p a}$

$f_{p}=E_{p} \varepsilon_{p}$

where $E_{p}=f_{p a} / \varepsilon_{p a}$

Region $A B$ :

$\varepsilon_{\mathrm{pa}}<\varepsilon_{\mathrm{p}} \leqslant \varepsilon_{\mathrm{pb}}$

$f_{p}=\frac{f_{p b} \varepsilon_{p b}-f_{p a} \varepsilon_{p a}}{\varepsilon_{p b}-\varepsilon_{p a}}+\frac{\varepsilon_{p a} \varepsilon_{p b}\left(f_{p a}-f_{p b}\right)}{\varepsilon_{p}\left(\varepsilon_{p b}-\varepsilon_{p a}\right)}$

Region $\mathrm{BC}$ :

$\varepsilon_{\mathrm{pb}}<\varepsilon_{\mathrm{p}} \leqslant \varepsilon_{\mathrm{pu}}$
$f_{\mathrm{p}}=f_{\mathrm{pb}}+\left(\frac{\varepsilon_{\mathrm{p}}-\varepsilon_{\mathrm{pb}}}{\varepsilon_{\mathrm{pu}}-\varepsilon_{\mathrm{pb}}}\right)\left(f_{\mathrm{pu}}-\mathrm{f}_{\mathrm{pb}}\right)$ 
Numerical values for the stresses and strains at each end of the curved region (points $A$ and $B$ ) and at ultimate (point $C$ ) can be obtained from experimental stressstrain curves. The assumed linear-hyperboliclinear shape for the stress-strain relationship has been shown previously $(1,2)$ to fit the experimental results closely.

\section{Envelope for Reversed Loading}

When cyclic tension-compression loading is applied the stress-strain envelope is assumed to be the monotonic loading stressstrain curve but with the origin displaced horizontally in some cases. The origin is displaced horizontally if the residual strain at zero stress is in the direction opposite to the direction in which the load is about to be applied. In such cases each loading run has a new origin for the envelope curve as shown in Fig. 2. The new origin for tensile loading is $\left(\varepsilon_{\mathrm{zmx}}, 0\right)$ where

$\varepsilon_{\text {zmx }}=\varepsilon_{0}-\frac{f_{o}}{E_{p}}$

where $\varepsilon_{O}$ is the maximum compressive strain and $f_{O}$ is the stress at the maximum compressive strain. The new origin for compressive loading is $\left(\varepsilon_{\mathrm{zmn}}, 0\right)$ where

$\varepsilon_{\mathrm{zmn}}=\varepsilon_{\mathrm{o}}-\frac{f_{\mathrm{o}}}{\mathrm{E}_{\mathrm{p}}}$

where $\varepsilon_{O}$ is the maximum tensile strain and $f_{0}$ is the stress at the maximum tensile strain. The assumed envelope is shown in Fig. 2. Note that the current stress-strain envelope for tensile loading must always commence at the original origin $(0,0)$ or to the left of it, and the current stress-strain envelope for compressive loading must always commence at the original origin $(0,0)$ or to the right of it. Thus for repeated loading of the same sign, or for reversed loading with inelastic straining occurring mainly in one direction, the origin remains at $(0,0)$. The steel stresses are not permitted to exceed the envelope values during loading.

\section{STRESS-STRAIN CURVE FOR CYCLIC LOADING}

\section{Assumed Form of the Stress-Strain Relationship}

For cyclic loading at stresses less than the envelope values, the following modified form of the Ramberg-Osgood function is assumed to give the stress-strain curve for loading runs after the first loading into the inelastic range.

$\phi E_{p}\left(\varepsilon_{p}-\varepsilon_{o}\right)=\left(f_{p}-f_{o}\right) \quad\left(1+\left|\frac{f_{p}-f_{o}}{f_{c h}-f_{o}}\right| r-1\right)$

where $\varepsilon_{p}, f_{p}$ are the strain and stress values at the point on the stress-strain curve; $\varepsilon_{0}, f_{0}$ are the strain and stress values at the beginning of the stress-strain curve; $\mathrm{f}_{\mathrm{Ch}}$ is the characteristic stress; $E_{\mathrm{p}}$ is the value of the modulus of elasticity from the initial loading run; $\phi$ is the modulus of elasticity modification factor (the ratio of the tangent modulus at the beginning of each curve te $\left.E_{p}\right)$; and $r$ is the Ramberg-Osgood parameter.

Eq. 6 applied to the unloading part of a cyclic stress-strain curve is illustrated in Fig. 3. The characteristics of the RambergOsgood function, Eq. 6, are shown in Fig. 4. It is to be noted that values of $r$ between 1 and $\infty$ give a range of sweeping curves which vary between a straight line when $r=1$ to a bilinear relationship with initial slope $\phi E$ when $r=\infty$. For all values of $r$ the function passes through a common point with coordinates

$\phi E_{p}\left(\frac{\varepsilon_{p}-\varepsilon_{o}}{f_{c h}-f_{o}}\right)=2,\left(\frac{f_{p}-f_{o}}{f_{c h}-f_{o}}\right)=1$.

The stress at this common point is the characteristic stress and the slope of the straight line joining the point to the origin is $\phi E_{p} / 2$.

\section{Assumed Characteristic Stress}

The characteristic stress $f_{c h}$ for use in Eq. 6 will be defined making use of the above observation concerning the coordinates of a common point with stress of magnitude $f_{c h}$. In the general case during cyclic loading the characteristic stress will be assumed to be the stress at which a straight line passing through $\left(\varepsilon_{0}, f_{0}\right)$ with slope $\phi \mathrm{E}_{\mathrm{p}} / 2$ intersects the linear plastic portion (branch BC of Fig. I) of the current stressstrain envelope (see Fig. 5), where $\varepsilon_{0}$ and $f_{O}$ are the strain and stress, respectively, at the beginning of the curve (i.e. the maximum strain and stress reached in the previous loading run).

Therefore, for loading into the tension range in repeated load tests $\left(\varepsilon_{\mathrm{zmx}}=\varepsilon_{\mathrm{zmn}}=0\right)$, the value of the characteristic stress will be given by the intersection of the line

$f_{p}=f_{o}+\left(\varepsilon_{p}-\varepsilon_{o}\right) \frac{\phi E_{p}}{2}$

and the line given by Eq. 3. Equating the $\varepsilon_{\mathrm{p}}$ values given by Eqs. 7 and 3 , and putting $f_{p}^{p}=f_{c h}$ in the resulting expression, gives

$f_{c h}=\frac{\phi E_{p} U\left(-\varepsilon_{p b}+\varepsilon_{o}+\frac{f_{p b}}{U}-\frac{2 f_{o}}{\phi E_{p}}\right)}{\phi E_{p}-2 U}$

where

$\mathrm{U}=\frac{f_{\mathrm{pa}}-f_{\mathrm{pb}}}{\varepsilon_{\mathrm{pu}}-\varepsilon_{\mathrm{pb}}}$

The equation for $f_{C h}$ for unloading in the tension range in repeated loaded tests is the same as Eqs. 8 and 9 except that care is necessary to ensure that the correct signs are substituted for the numerical values of the stresses and strains. The best method to check signs is to ensure that the substituted signs give the correct values for $f_{p}$ when placed in Eqs. 7 and 3 .

When the loading is reversed, and $\varepsilon_{\text {zmx }}$ and $\varepsilon_{\text {zmn }}$ are not equal to zero, the equation for the line given by Eq. 3 should be modified so that the origin is displaced as in Fig. 2 and the modified equation used with Eq. 7 to find $\mathrm{f}_{\mathrm{Ch}}$. It will be found in this case that $f_{\mathrm{ch}}$ for loading and unloading curves will be given by an equation similar to Eqs. 8 and 9 with the addition of $\varepsilon_{\mathrm{zmx}}$ or $\varepsilon_{\mathrm{zm}}$ (with the appropriate sign) within the bracket in the numerator of the right hand side of Eq. 8 . 


\section{TESTS ON STEEL SPECIMENS}

Six samples of prestressing wire were tested under repeated tensile loading. The samples were from 0.276 in $(7 \mathrm{~mm})$ diameter stress relieved steel prestressing wire manufactured by Sumitomo Electrical Industries Ltd., Japan. All samples were from the same batch and had a tensile strength of about $240 \mathrm{ksi}(1.655 \mathrm{MPa})$.

The specimens were loaded in an Avery testing machine. The load was measured using a Philips 10 ton $(99.6 \mathrm{kN})$ load cell. The primary arms of the electrical circuit of the load cell were powered with an input voltage, and the output voltage from the secondary arms (measuring load) was recorded on the $y$ axis of an $x-y$ pen recorder. The strain was measured over a 3 in $(76.2 \mathrm{~mm})$ gauge length using a linear variable displacement transformer (LVDT) which was clamped to the wire. The LVDT was powered with an input voltage, and the output voltage recorded on the $x$ axis of the $x-y$ rtcorder. The load cell was caliorated using the Avery testing machine and the LVDT using a micrometer screw device. This graphical method of recording the stress-strain curves allowed the complete history of stress-strain behaviour during the loading cycles to be obtained during the tests.

The specimens were subjected to load cycles in the tension range with gradually increasing inelastic strains. Figs. 10 to 15 show the experimental stress-strain curves. The loading was all in the tensile range because of the difficulty, with small diameter steel, of ensuring that compressive loading was axial and that buckling was prevented.

\section{REGRESSION ANALYSIS OF TEST RESULTS}

Modulus of Elasticity Modification Factor, $\phi$

The experimental stress-strain curves for each load cycle were used to determine the modulus of elasticity modification factor, $\phi$. The ratio $\phi$ of the initial slope of the curve, measured in each loading and unloading run, to the modulus of elasticity measured in the elastic region of the first loading run is shown plotted against the current value of the maximum imposed steel strain $\varepsilon_{m}$ in Fig. 6 . The plotted points show a clear trend of decreasing $\phi$ with increasing $\varepsilon_{\mathrm{m}}$. A regression analysis was used to fit a second order parabola to these values. The resulting relationship is

$\phi=58.3 \varepsilon_{m}^{2}-7.51 \varepsilon_{m}+1.04$

but $\phi$ is not to exceed unity. The empirical Eq. 10 is shown plotted in Fig. 6. A trend of decreasing slope of the unloading curve with increasing maximum imposed steel strain was also observed by Blakeley and Park $(1,2)$.

\section{Ramberg-Osgood Parameter, $r$}

A regression analysis was performed on the experimental stress-strain curves for each load cycle in order to find the RambergOsgood parameter $r$ from Eq. 6 , with $\phi$ defined by Eq. 10 and $f_{c h}$ defined by Eqs. 8 and 9. To perform this analysis (3), Eq. 6 was first made linear in $r$ using the first two terms of the Taylor series as described by Draper and Smith $(5)$. Then regression analysis was conducted to determine $r$ for each of the loading and unloading curves of each load cycle for each specimen so that the sum of the squares of the differences between the experimentally measured strain and the strain predicted by Eq. 6 (with $\phi$ from Eq. 10 and $\mathrm{f}_{\mathrm{Ch}}$ from Eqs. 8 and 9) at particular stress levels was minimized. The results of this regression analysis for $r$ for the six tests specimens are shown in Table 1.

The values of $r$ so determined were then plotted against various possible dependent factors. It was observed that $r$ was apparently dependent on the plastic strain imposed in the previous loading run, $\varepsilon$, and on whether the curve was for loading or unloading. Values of $r$ for both loading and unloading (from Table l) are shown plotted against $\varepsilon_{\mathrm{pl}}$ in Figs. 7 and 8 . Correlation of $r$ with ahy other possible factors was poor. Linear relationships relating $r$ were fitted to the loading and unloading results in Figs. 7 and 8 , weighted according to the inverse of the standard deviation for stress for the particular run. Because of the wide scatter of points it was considered that any fitted relationship more complicated than a linear one was unwarrented. The following relationships were obtained.

For loading in tension

$r=57.9-59,100 \varepsilon_{\mathrm{pl}}$

but not less than 20

For unloading in tension

$r=5.00-194 \varepsilon \mathrm{pl}$

but not less than 3.5

The empirical Eqs. 11 and 12 are shown plotted in Figs. 7 and 8.

MANNER OF USE OF CYCLIC STRESS-STRAIN EQUATIONS

The proposed model for cyclic stressstrain behaviour is described by Eqs. 1 to 12. Eqs. 1 to 3. define the monotonic stress-strain curve and hence apply to the first loading run into the inelastic range. Subsequent loading runs are described by Eqs. 6 to 12 , with the stipulation that the stress level reached should not exceed that given by the current stress-strain envelope described by the monotonic stressstrain curve with the zero stress origin given either at the original origin or, in the case of significant reversed loading, by a laterally displaced origin defined by Eqs. 4 and 5. When the origin of the envelope curve is displaced, Eq. 8 for $f_{\mathrm{ch}}$ needs to be modified to include the effect of the displaced origin.

In order to allow for small stress cycles which do not significantly effect the stress-strain history, it was further assumed that if the plastic strain imposed in a loading or unloading run was small (less than 0.001 for loading in the tension direction, or less than 0.0003 for unloading in tension including any loading in 
compression), then on reloading the new loading curve is only continued until the previous loading curve is reached and then the previous loading curve is followed. This constraint on the cyclic stress-strain relationship is illustrated in Fig. 9.

\section{COMPARISON OF EXPERIMENTAL RESULTS WITH} PROPOSED CYCLIC STRESS-STRAIN MODEL

Figs. 10 to 15 compare the stress-strain curves derived from the proposed model presented in this paper with the experimentally measured stress-strain curves from the six specimens. The curves derived from the stress-strain model were calculated between the experimental strain values at which strain reversals took place. The stress-strain curves derived from the proposed model are seen to coincide reasonably accurately with the experimental stress-strain curves. The unloading curves coincide particularly accurately. However the reloading curves proposed by the model tend to overestimate the stress at low strains and underestimate the stress at higher strains, but the error in stress is not large. In all but a few cases the widths of the hysteresis loops predicted by the model are the same as those obtained experimentally.

It should be noted that use of an accurate stress-strain model is important because if the difference between the predicted and experimental stresses immediately prior to strain reversal is large, the predicted curve becomes out-ofphase with the experimental curve and significant errors can arise.

It should also be emphasized that the empirical equations for the proposed cyclic stress-strain model have been derived from experimental results obtained from prestressing steel with strain imposed in the tension range only, for one batch of steel, and for slow (static) strain rates. Further tests are required, particularly to check the accuracy of the moajel when reversed loading causes significant inelastic strains in both the tension and compression range. Tests are also needed to investigate the effect of high rates of loading such as in a structure subjected to seismic ground motions, and to investigate the possible change in steel mechanical properties due to strain ageing after cyclic loading in the elastic range.

\section{APPLICATIONS OF THE CYCLIC STRESS-STRAIN MODEL}

The proposed model for the stress-strain behaviour of cyclically loaded prestressing steel in the inelastic range emphasizes that the stress-strain curve becomes nonlinear over much of the loading range. Also, a pronounced hysteresis occurs in the stressstrain loop for repeated loading of the same sign, particularly at high strains. The proposed stress-strain model has three main applications.

The first application is in the determination of the theoretical moment-curvature characteristics of prestressed concrete members subjected to cyclic (reversed) flexure. It has been found previously $(1,2,3)$ that it is necessary to include the effect of hysteresis in the cyclic stress-strain idealization for prestressing steel in order to obtain good agreement between theoretical and experimental cyclic (reversed) moment-curvature relationships. Also, since energy dissipation is a function of the area of the hysteresis loops, it is important to use a reasonably accurate model for the moment-curvature behaviour to obtain an accurate prediction of the response of prestressed concrete structures to severe ground motions. Note that, because of the initial tensile steel strain due to prestress, the stress in the prestressing steel will remain in the tension range during cyclic (reversed) flexure, unless the displacements are sufficiently great to result in high compressive strains in the concrete.

The second application is in the determination of the buckling load of prestressing tensons in highly strained compression regions of prestressed concrete members during severe cyclic (reversed) flexure in the inelastic range, after the concrete cover has crushed and the steel is laterally restrained only at the stirrups. The tangent modulus of the prestressing steel at compressive stresses less than the initial limit of proportioning can be significantly lower than the modulus of elasticity of the steel and this could lead to buckling of tendons at lower levels of compressive steel stress than expected from monotonic load tests.

The third application is in the calculation of the stresses in prestressing tendons from the strain histories measured during loading.

\section{CONCLUSIONS}

Equations defining the stress-strain curve for prestressing steel wire under cyclic loading have been presented using the Ramberg-Osgood function with empirical constants which depend on the strain reached in the previous loading run and the characteristics of the monotonic stress-strain curve. The stress-strain curve for monotonic loading, with suitably adjusted origin of coordinates in the case of significant reversed loads, is used to describe the envelope curve which the steel stresses cannot exceed. The experimental stress-strain curves obtained from samples of 0.276 in $(7 \mathrm{~mm})$ diameter stress relieved prestressing steel wire were predicted with good accuracy by the proposed equations.

\section{ACKNOWLEDGEMENTS}

The work described herein formed part of an investigation executed in the Department of Civil Engineering of the University of Canterbury, New Zealand, by K. J. Thompson during postgraduate studies for the degree of Doctor of Philosophy, supervised by R. Park.

The financial assistance of the following New Zealand organizations is gratefully acknowledged: University Grants Committee, Ministry of Works and Development, Building Research Association, Prestressed Concrete Institute, and the University of Canterbury. 


\section{REFERENCES}

1. Blakeley, R.W.G., "Ductility of Prestressed Concrete Frames Under Seismic Loading", Doctor of Philosophy Thesis, University of Canterbury, New Zealand, 1971, p.230 plus appendices.

2. Blakeley, R.W.G. and Park, R., "Prestressed Concrete Sections with Cyclic Flexure", Journal of the Structural Division, ASCE, Vol. 90, No. ST8, August 1973, pp.1717-1742.

3. Thompson, K. J.," "Ductility of Concrete Frames Under Seismic Loading", Doctor of Philosophy Thesis, University of Canterbury, New Zealand, 1975, p.34l plus appendices.

4. Paranagama, D.D.O. and Edwards, A. D. "Moment-Deformation Characteristics of Pretensioned Beams Subject to Fluctuating Loads", PCI Journal, Vol. 14, No. 4, August 1969, pp. 62-74.

5. Draper, N. R. and Smith, N., "Applied Regression Analysis", John Wiley and Sons, New York, 1966, p.407.

\section{NOTATION}

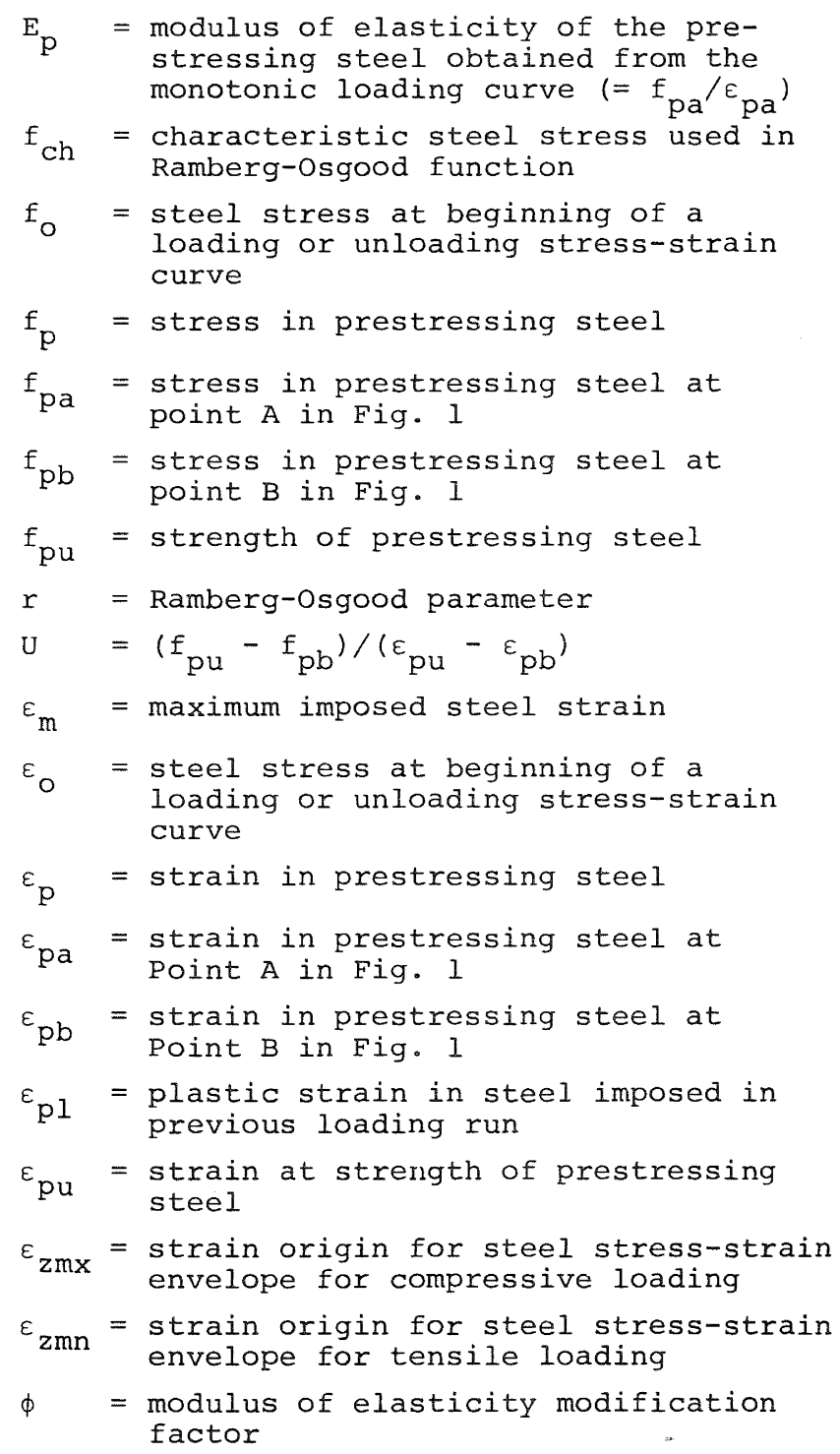


TABLE 1

RESULTS OF REGRESSION ANALYSIS FOR RAMBERG-OSGOOD

PARAmeter, $R$

\begin{tabular}{|c|c|c|}
\hline Specimen & $\begin{array}{l}\text { Loading } \\
\text { Run } \\
\text { Number }\end{array}$ & $r$ \\
\hline 1 & $\begin{array}{r}2 \\
3 \\
4 \\
5 \\
7 \\
8 \\
9 \\
10 \\
11 \\
12 \\
13 \\
14 \\
15 \\
16 \\
17 \\
18 \\
19 \\
20 \\
21\end{array}$ & $\begin{array}{r}6.62 \\
65.51 \\
5.65 \\
62.22 \\
38.76 \\
4.59 \\
44.30 \\
4.49 \\
39.20 \\
4.60 \\
35.57 \\
4.40 \\
29.33 \\
4.29 \\
28.93 \\
4.88 \\
28.65 \\
4.51 \\
22.84\end{array}$ \\
\hline 2 & $\begin{array}{r}2 \\
3 \\
4 \\
5 \\
6 \\
7 \\
8 \\
9 \\
10 \\
11 \\
12 \\
13 \\
14\end{array}$ & $\begin{array}{r}8.07 \\
66.71 \\
4.57 \\
100.00 \\
4.31 \\
100.00 \\
4.23 \\
16.29 \\
4.65 \\
100.00 \\
4.03 \\
38.14 \\
4.07\end{array}$ \\
\hline 3 & $\begin{array}{r}2 \\
3 \\
4 \\
5 \\
6 \\
7 \\
8 \\
9 \\
10 \\
11 \\
12 \\
13 \\
14 \\
15\end{array}$ & $\begin{array}{r}6.09 \\
41.18 \\
4.53 \\
60.86 \\
4.03 \\
100.00 \\
4.08 \\
62.50 \\
3.93 \\
78.71 \\
3.81 \\
20.85 \\
3.68 \\
70.23\end{array}$ \\
\hline
\end{tabular}

\begin{tabular}{|c|c|c|}
\hline Specimen & $\begin{array}{l}\text { Loading } \\
\text { Run } \\
\text { Number }\end{array}$ & $r$ \\
\hline 4 & $\begin{array}{r}2 \\
3 \\
4 \\
5 \\
6 \\
7 \\
8 \\
9 \\
10 \\
13 \\
14 \\
15 \\
16\end{array}$ & $\begin{array}{r}4.47 \\
48.59 \\
4.57 \\
55.20 \\
4.26 \\
49.02 \\
4.94 \\
44.56 \\
4.60 \\
44.18 \\
4.61 \\
37.65 \\
4.84\end{array}$ \\
\hline 5 & $\begin{array}{l}2 \\
3 \\
4 \\
5 \\
6\end{array}$ & $\begin{array}{r}3.50 \\
56.33 \\
3.86 \\
52.54 \\
3.63\end{array}$ \\
\hline 6 & $\begin{array}{r}2 \\
3 \\
4 \\
5 \\
6 \\
7 \\
8 \\
9 \\
10 \\
11 \\
12\end{array}$ & $\begin{array}{r}4.47 \\
44.84 \\
4.84 \\
43.60 \\
4.71 \\
37.69 \\
4.83 \\
34.16 \\
4.63 \\
30.55 \\
4.41\end{array}$ \\
\hline
\end{tabular}




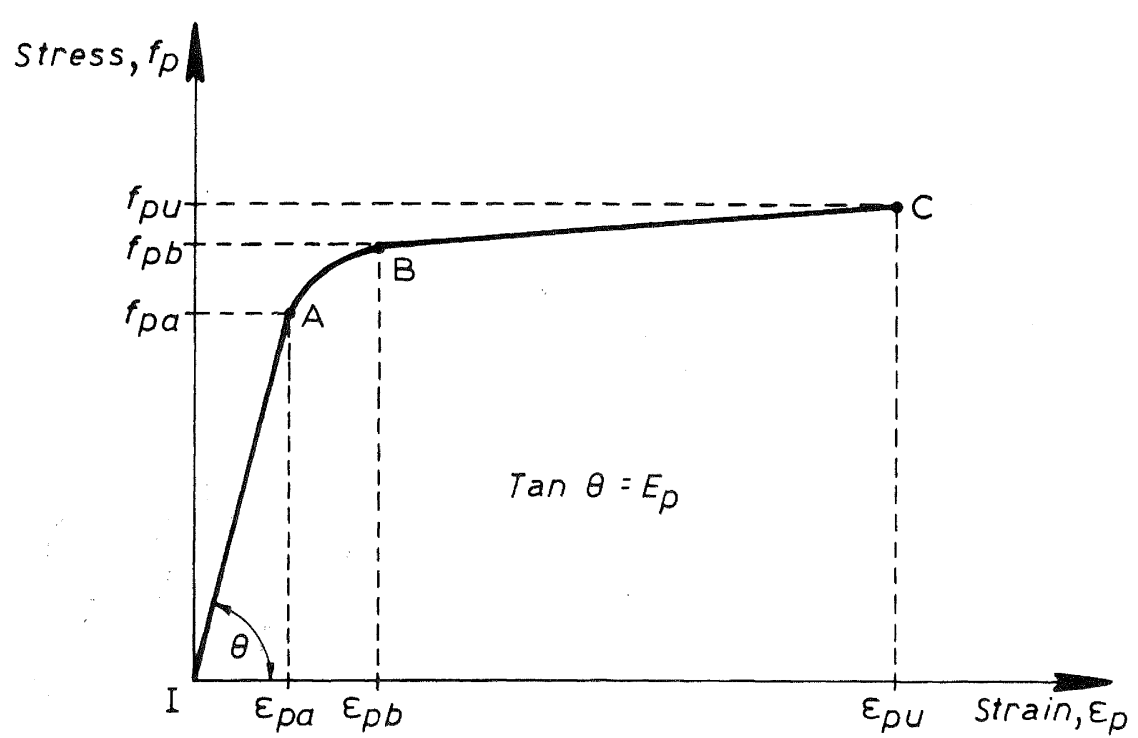

FIGURE 1: MONOTONIC STRESS-STRAIN

RELATIONSHIP FOR PRESTRESSING STEEL

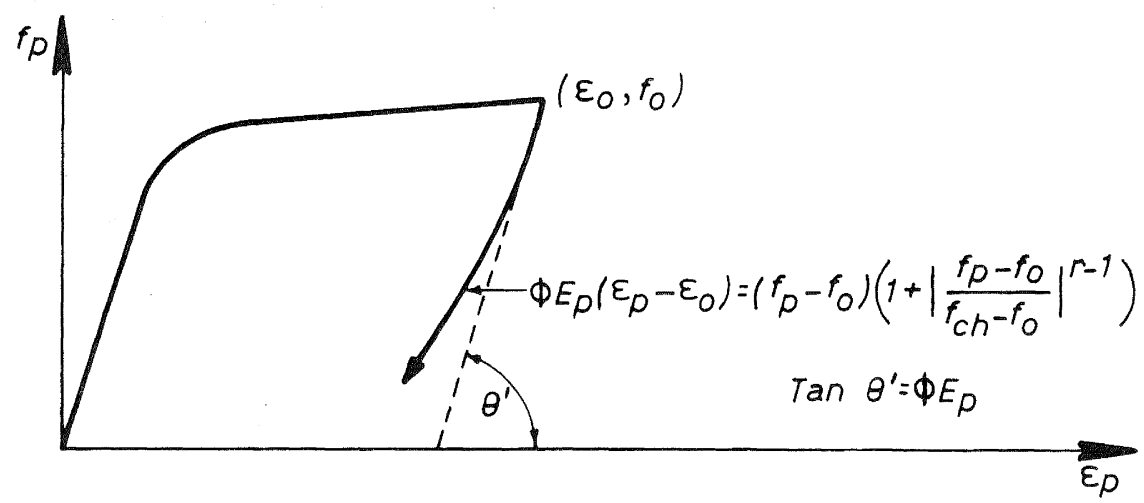

FIGURE 3: CYCLIC STRESS-STRAIN RELATIONSHIP FOR PRESTRESSING STEEL

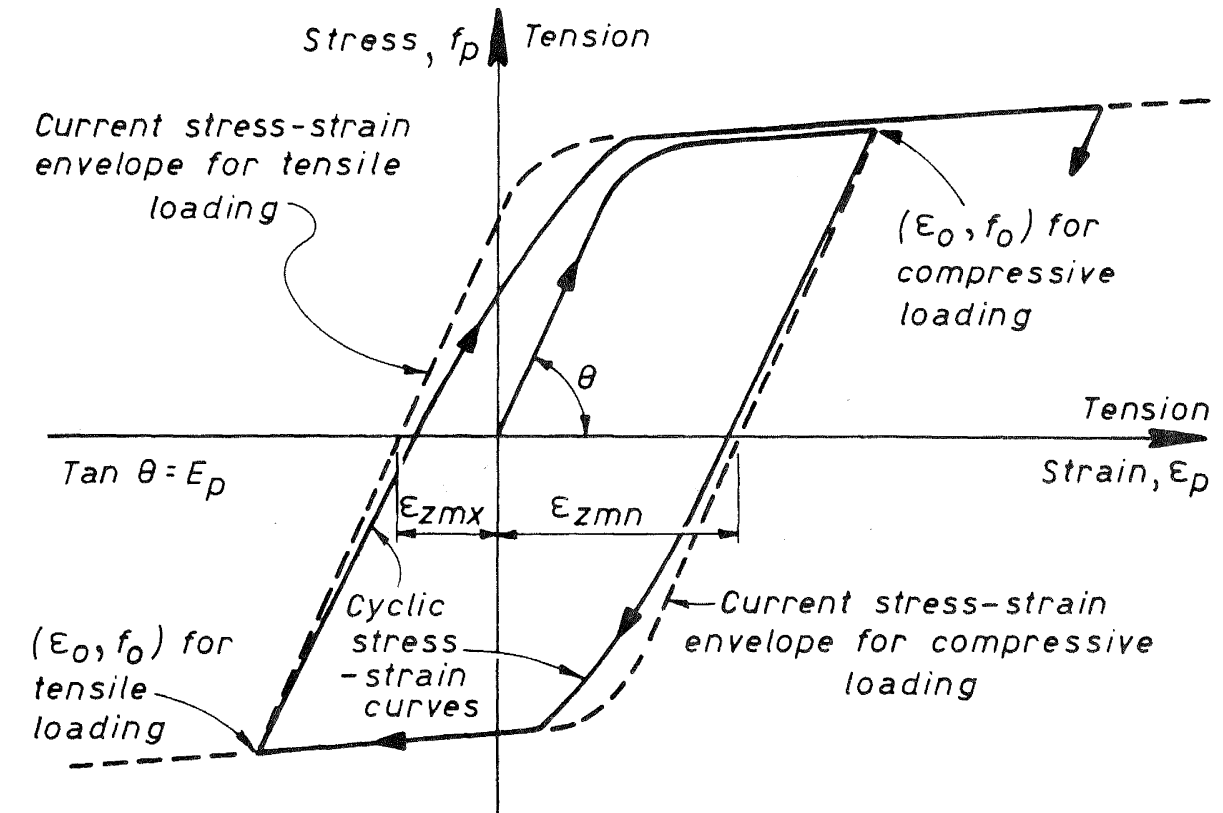

FIGURE 2: STRESS-STRAIN ENVELOPE FOR REVERSED LOADING

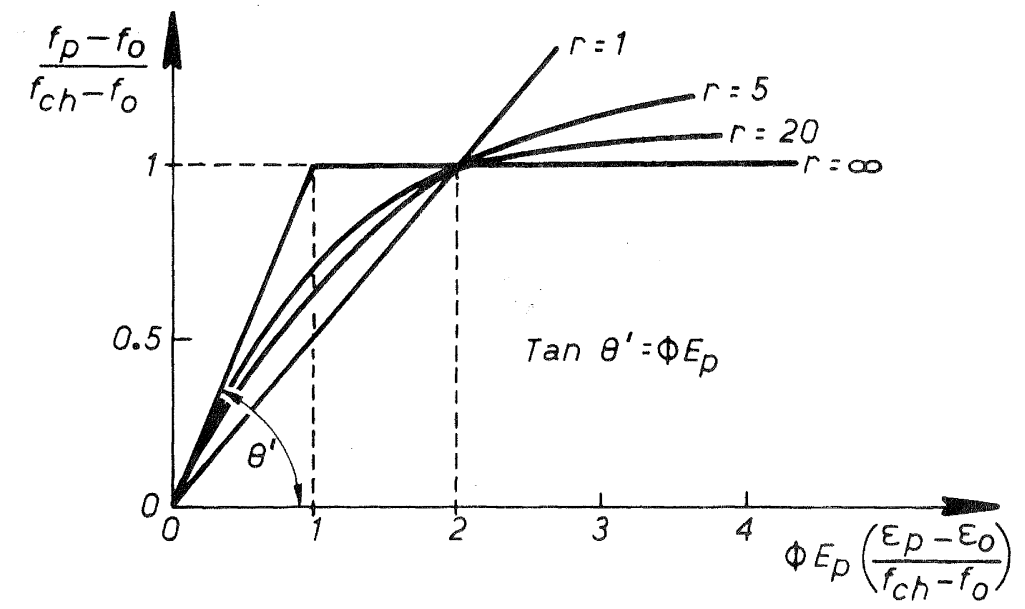

FIGURE 4: CURVES GIVEN BY RAMBERG-OSGOOD FUNCTION, EQ. 6 


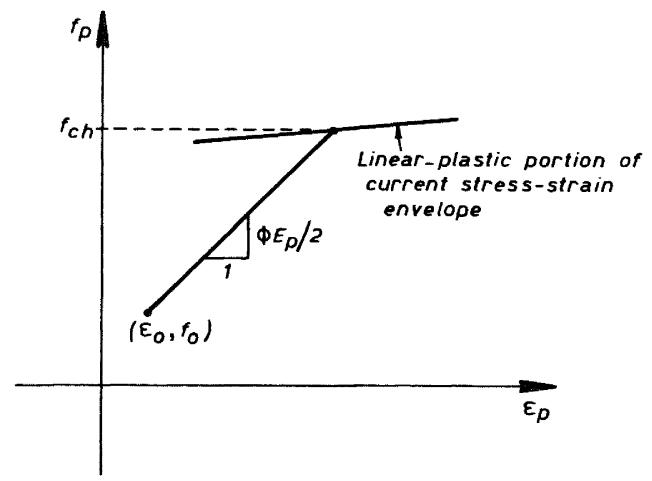

FIGURE 5: ASSUMED CHARACTERISTIC STRESS

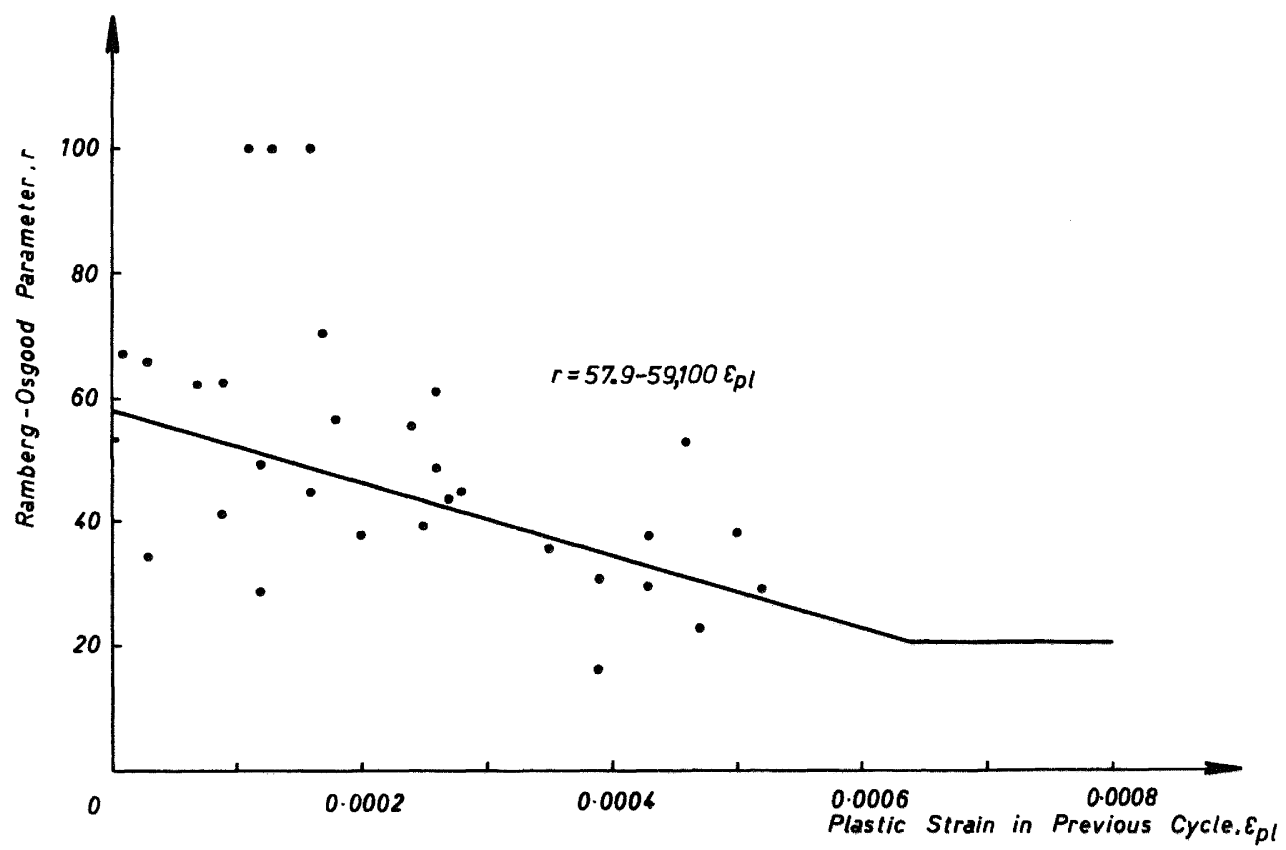

FIGURE 7: RELATIONSHIP BETWEEN RAMBERG-OSGOOD PARAMETER I AND PLASTIC STRAIN IMPOSED IN PREVIOUS LOADINGRUN \& PI FOR LOADING IN TENSION

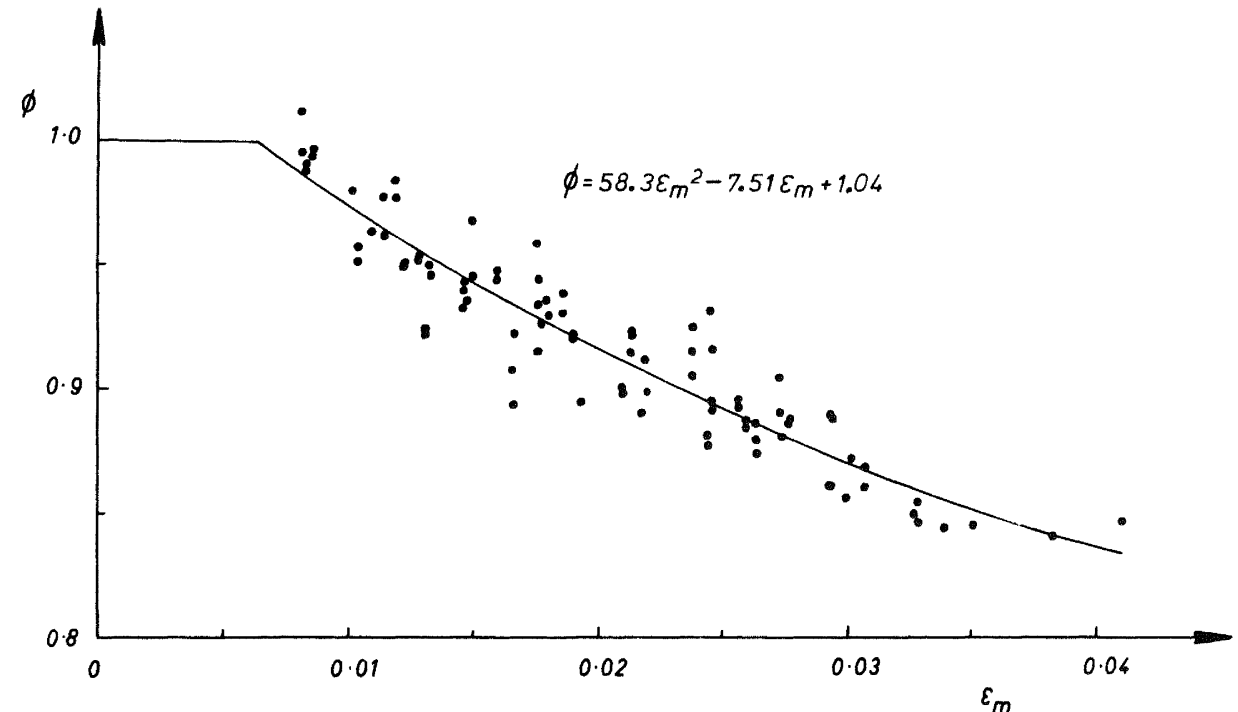

FIGURE 6: RELATIONSHIP BETWEEN MODULUS OF ELASTICITY MODIFICATION FACTOR $\varnothing$ AND MAXIMUM IMPOSED STRAIN $\&_{m}$

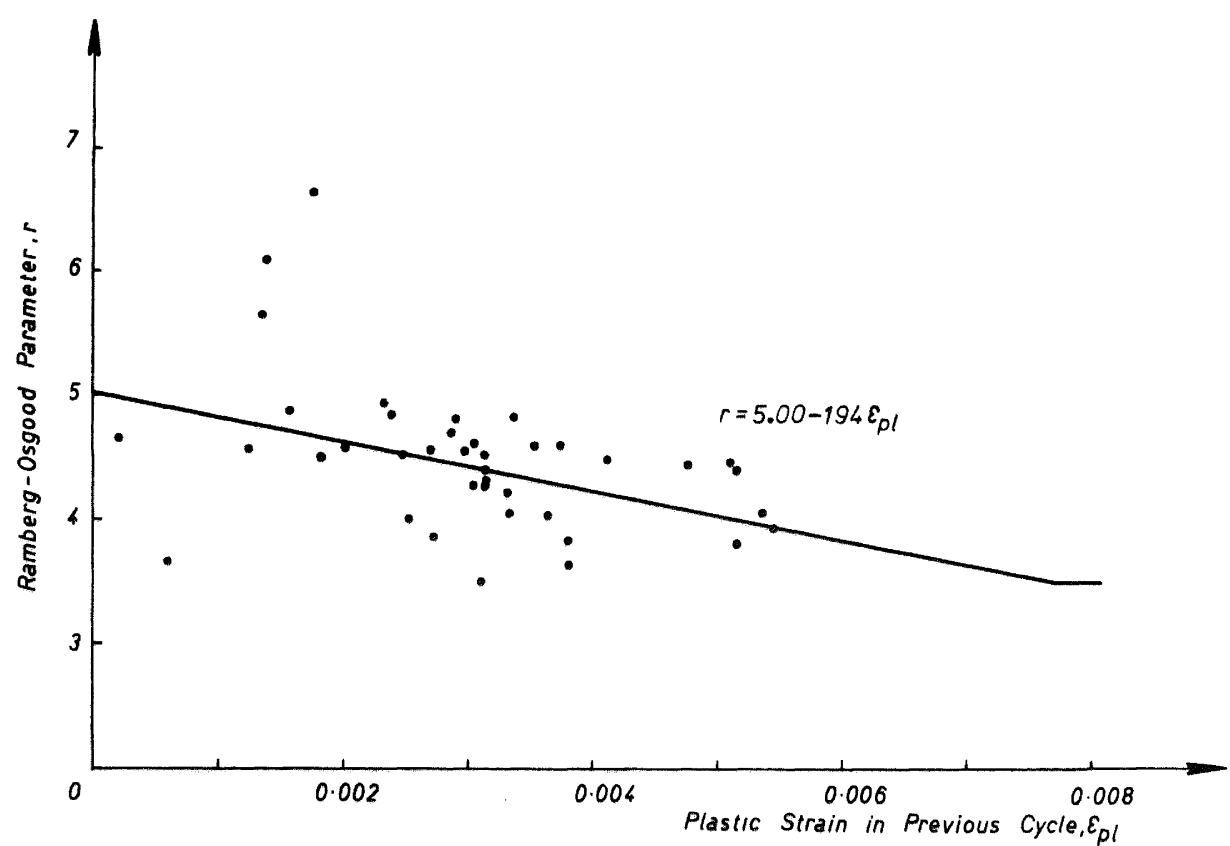

FIGURE 8: RELATIONSHIP BETWEEN RAMBERG-OSGOOD PARAMETER I AND PLASTIC STRAIN IMPOSED IN PREVIOUS LOADING RUN \& PI FOR UNLOADING IN TENSION 


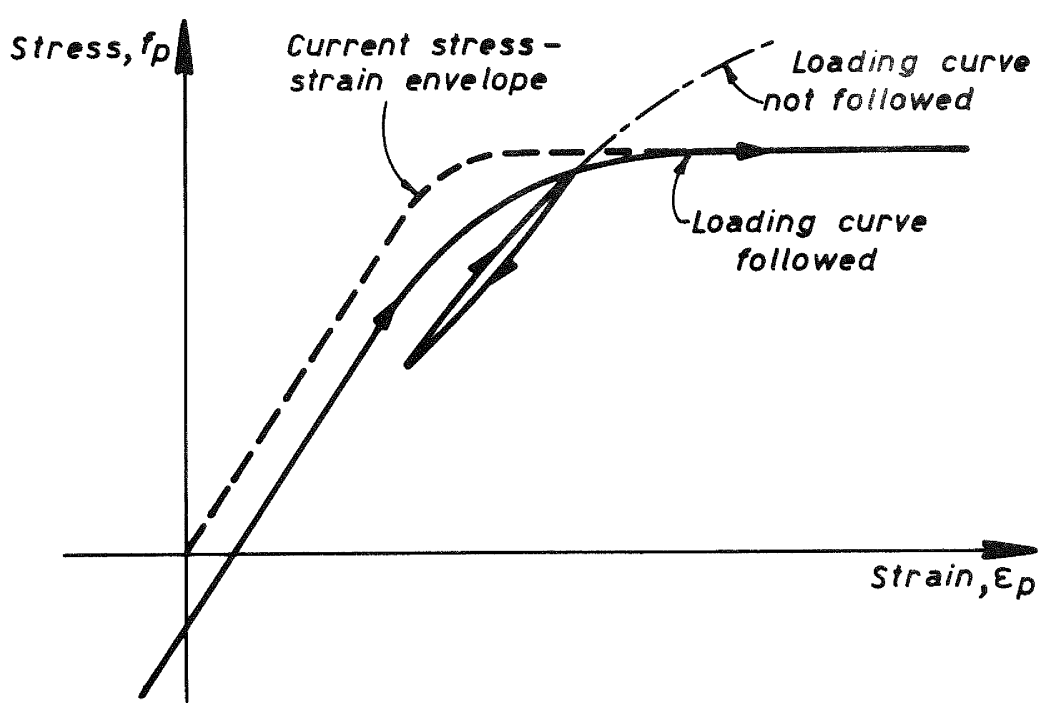

FIGURE 9: CONSTRAINTS ON CYCLIC STRESS-STRAIN RELATIONSHIPS

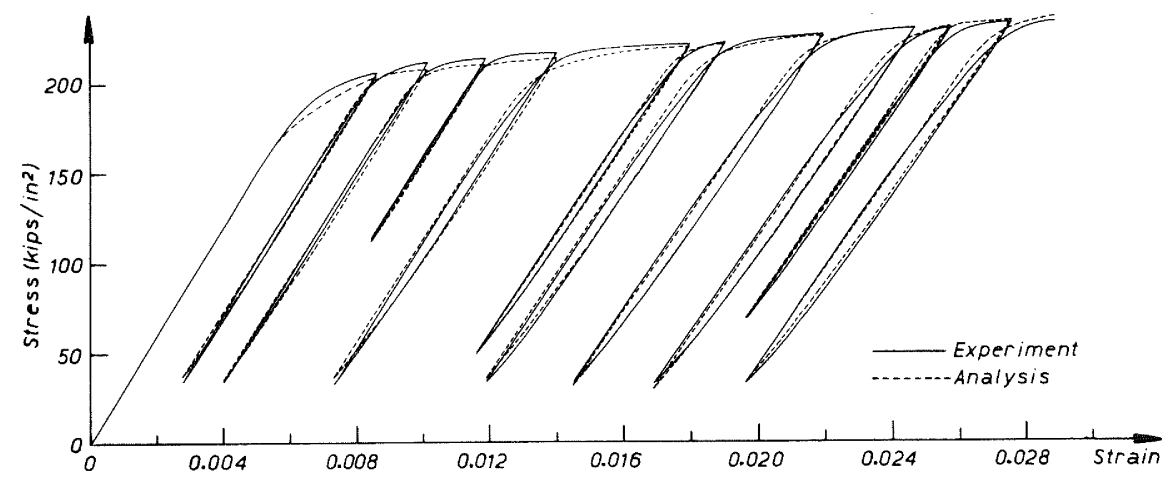

FIGURE 10: STRESS-STRAIN CURVES FOR PRESTRESSING STEEL SPECIMEN $1\left(1 \mathrm{kip} / \mathrm{in}^{2}=6.89 \mathrm{MPa}\right)$.

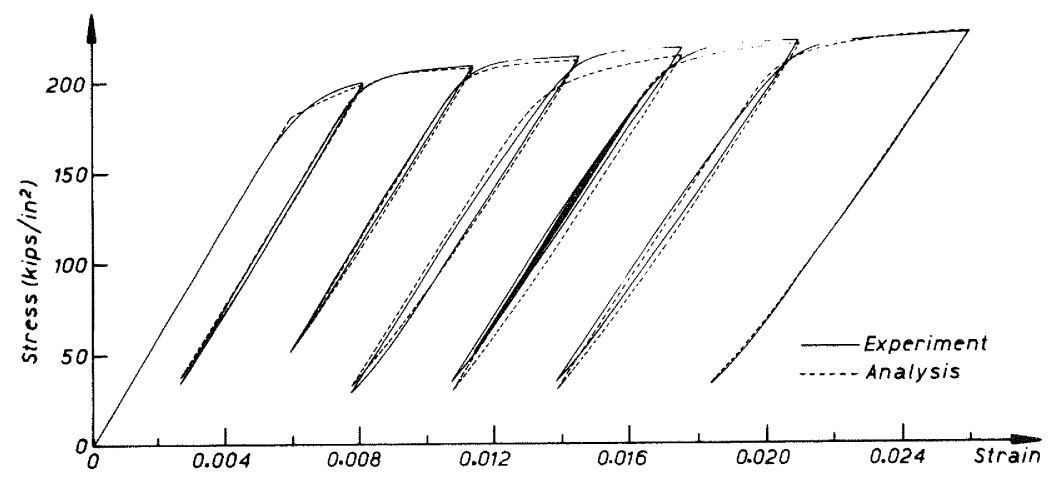

FIGURE 11: STRESS-STRAIN CURVES FOR PRESTRESSING STEEL SPECIMEN $2(1 \mathrm{kip} / \mathrm{in} 2=6.89 \mathrm{MPa})$ 


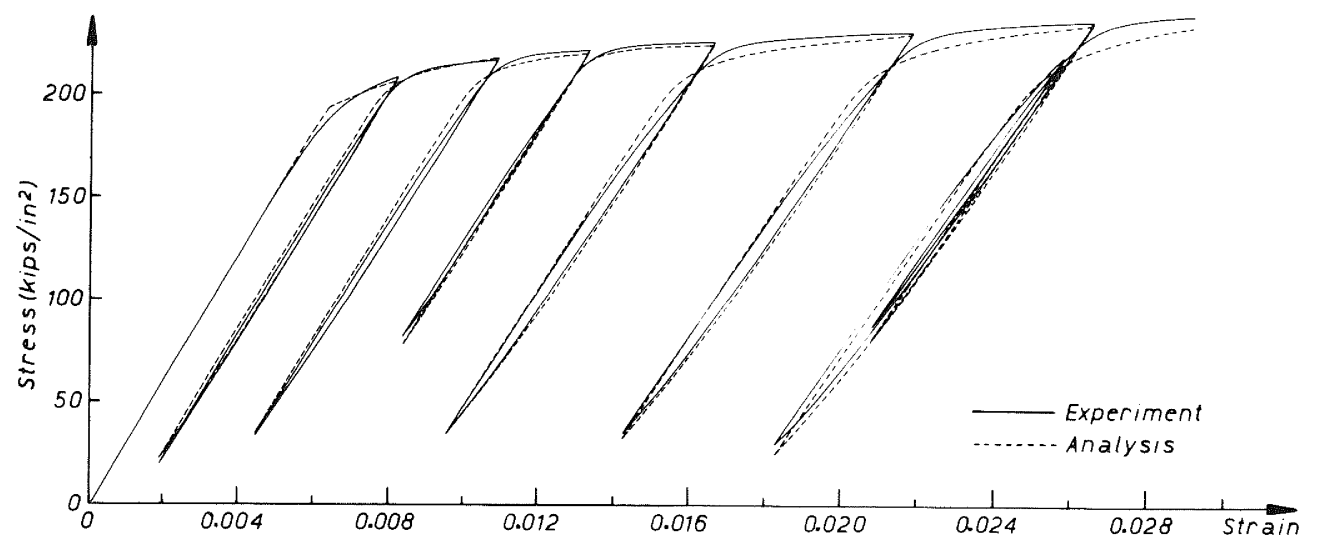

FIGURE 12: STRESS-STRAIN CURVES FOR PRESTRESSING STEEL SPECIMEN $3\left(1 \mathrm{kip} / \mathrm{in}^{2}=6.89 \mathrm{MPa}\right)$
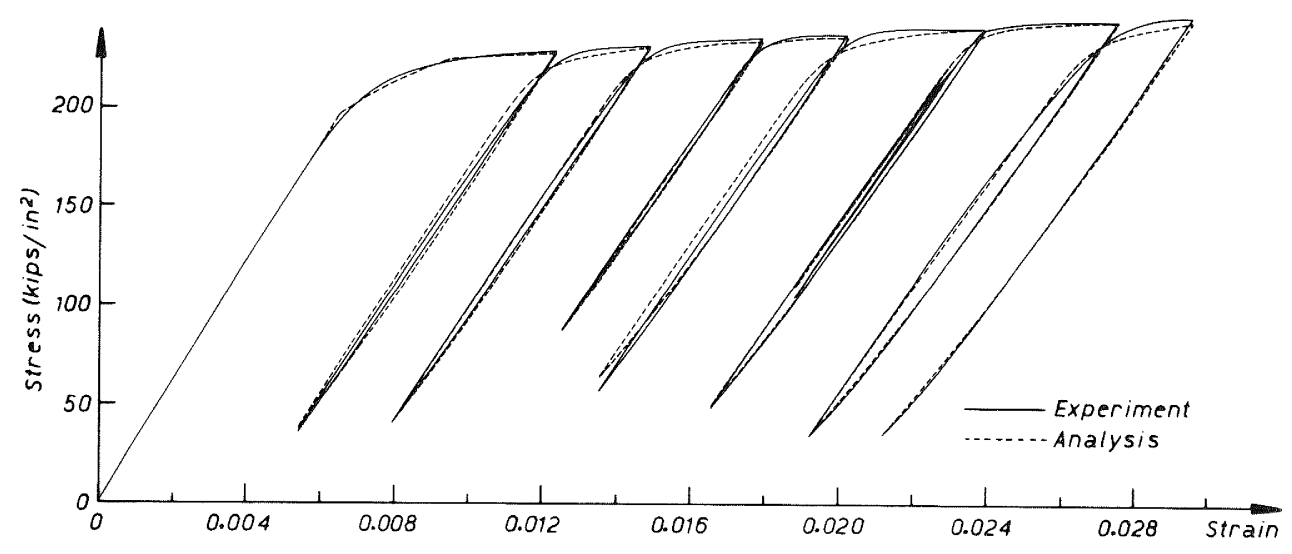

FIGURE 13: STRESS-STRAIN CURVES FOR PRESTRESSING STEEL SPECIMEN $4(1 \mathrm{kip} / \mathrm{in} 2$

$=6.89 \mathrm{MPa}$ )
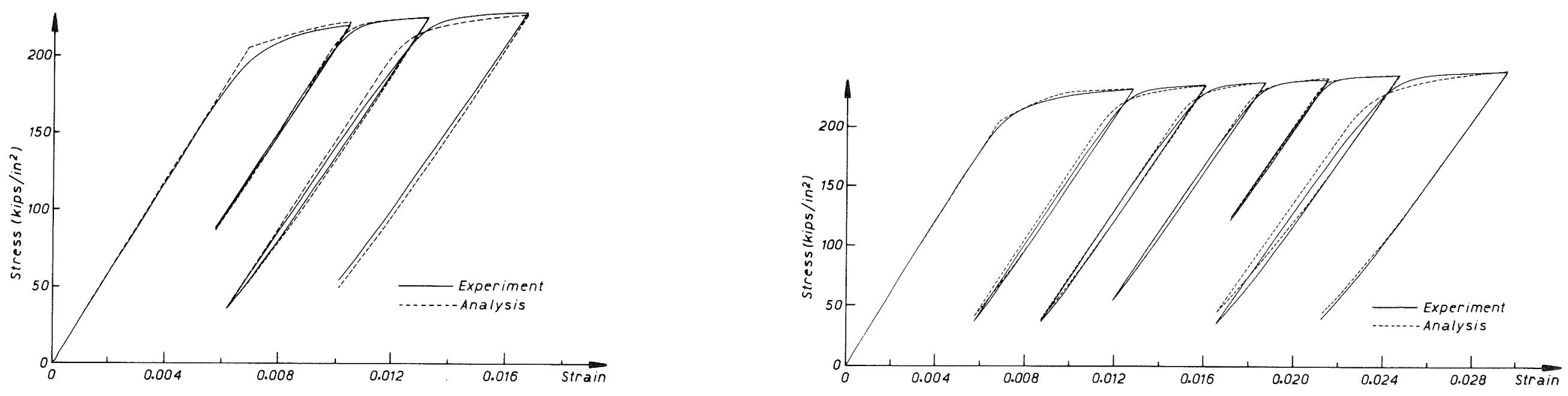

FIGURE 14: STRESS-STRAIN CURVES FOR PRESTRESSING STEEL SPECIMEN 5 $\left(1 \mathrm{kip} / \mathrm{in}^{2}=6.89 \mathrm{MPa}\right)$

FIGURE 15: STRESS-STRAIN CURVES FOR PRESTRESSING STEEL SPECIMEN $6(1 \mathrm{kip} / \mathrm{in} 2$

$=6.89 \mathrm{MPa})$ 